\title{
Effect of Neoadjuvant Hormone Therapy on Resection Margin and Survival Prognoses in Locally Advanced Prostate Cancer after Prostatectomy Using Propensity-Score Matching
}

\author{
Sung Han Kim $\left(\mathbb{D},{ }^{1}\right.$ Eun Young Park, ${ }^{2}$ Jungnam Joo $\mathbb{D}^{\mathrm{D}},{ }^{2}$ Jae Young Joung $\mathbb{D}$, \\ Ho Kyung Seo ${ }^{D},{ }^{1}$ Jinsoo Chung $\left(D,{ }^{1}\right.$ and Kang Hyun Lee ${ }^{1}$ \\ ${ }^{1}$ Department of Urology, Center for Prostate Cancer, Research Institute and Hospital of National Cancer Center, \\ Goyang, Republic of Korea \\ ${ }^{2}$ Biometrics Research Branch, Division of Cancer Epidemiology and Prevention, Research Institute and Hospital of \\ National Cancer Center, Goyang, Republic of Korea
}

Correspondence should be addressed to Kang Hyun Lee; uroonco@ncc.re.kr

Received 14 February 2018; Accepted 13 November 2018; Published 6 December 2018

Guest Editor: Franco M. Buonaguro

Copyright (C) 2018 Sung Han Kim et al. This is an open access article distributed under the Creative Commons Attribution License, which permits unrestricted use, distribution, and reproduction in any medium, provided the original work is properly cited.

\begin{abstract}
This study aimed to investigate the effect of neoadjuvant hormone therapy (NHT) on resection margin positivity, biochemicalrecurrence- (BCR-) free survival, and overall survival (OS) in 176 patients with locally advanced prostate cancer (LAPC) treated with radical prostatectomy using propensity-score matching, including 79 (44.9\%) patients treated with the NHT. Fifty pairs of one-to-one propensity-score matching were matched to investigate the pure effect of NHT on resection margin positivity, BCR, and OS with a statistical significance of $p<0.050$. Before matching, NHT, tumor volume percentage, and extracapsular extension were significant factors for resection margin positivity ( $p \leq 0.001)$; however, after matching, NHT became insignificant in the multivariate analysis $(p=0.084)$. In the survival analysis, NHT was not associated with BCR or OS before and after matching (BCR: hazard ratio, 1.35 and 0.84 , respectively; OS: hazard ratio, 1.05 and 0.77 , respectively; $p \geq 0.539$ for all). Conversely, PSA level (HR, 2.23), extracapsular extension ( $\mathrm{HR}, 2.10)$, and lymphovascular invasion (HR, 1.85) were significant factors for BCR ( $p \leq 0.001$ for all), but none were significant factors for OS in the propensity-score matching analysis ( $p \geq 0.948)$. Therefore, NHT was not a significant factor for resection margin positivity, BCR-free survival, and OS before and after propensity-score matching in patients with LAPC.
\end{abstract}

\section{Introduction}

Prostate cancer (PC) results from an androgen-dependent tumor in males. The androgen-producing mechanism is a key therapeutic objective in the treatment of PC. In 1964, Scott and colleagues introduced the idea of encouraging recurrence-free survival in men with advanced PC by treating with radical prostatectomy (RP) and androgen deprivation therapy or androgen blocking hormonal therapy (HT). Presently, HT is one of the standard therapeutic options for PC in order to inhibit the growth of PC, especially for recurred PC after prostatectomy or advanced PC [1].

The rationale for using HT in the neoadjuvant setting (NHT) is to reduce the size of the tumor before surgery in an effort to improve surgical treatment for locally advanced
PC. In combination with RP, NHT has been shown to result in improvements in both clinical and local pathological outcomes, including achieved pathologic T0 with RP [2]. Improvements include downstaging and organ confinement, with a reduction in positive resection margin (RM) rates and a decrease of lymph node involvement $[3,4]$. However, because of existing differences in enrolled patients' baseline characteristics in prior studies $[1,4]$, there still remains uncertainty as to NHT's direct clinical and pathological impact in locally advanced PC prior to RP, especially in the aspects of overall survival (OS) and disease-free survival [1] that the current EAU guideline 2017 does not recommend NHT $[3,4]$.

To the best of our knowledge, no studies have evaluated the pure effect of NHT itself on RM positivity and diseasefree survival in the aspect of prostate-specific antigen (PSA) 
outcome, called biochemical recurrence (BCR), after all of the preoperative and intraoperative variables were conditionally corrected using matching. Therefore, this study aimed to evaluate the effect of NHT on RM positivity, BCR, and OS in patients with locally advanced PC who underwent RP. Patients were allocated into groups based on whether they were or were not administered NHT, and we used the propensity-score (PS) matching method to adjust for the different baseline clinicopathological variables between the two groups.

\section{Materials and Methods}

2.1. Ethical Statements. All study protocols were conducted according to the ethical guidelines of the "World Medical Association Declaration of Helsinki-Ethical Principles for Medical Research Involving Human Subjects." This study was approved by the Institutional Review Board (IRB) of the Research Institute and Hospital National Cancer Center (IRB No. NCCNCS 05-049). All enrolled patients' informed consents were waived by the IRB.

2.2. Patients and Tissue Samples. From March 2004 to December 2015, 176 consecutive locally advanced patients with PC who underwent RP and were clinically staged at either $\geq \mathrm{T} 3$ or $\mathrm{N}+$ at the Prostate Cancer Center within the National Cancer Center in Goyang, Korea, were retrospectively identified. Patients had complete medical records that included clinicopathological and prognostic information, such as follow-up duration of $>6$ months and survival outcomes. Those who did not reach a postoperative undetectable PSA level of $<0.2 \mathrm{ng} / \mathrm{mL}$ were not included, as well as those who had a history of being treated with NHT for at least 3 months. Patients were then divided into NHT and nonNHT groups. Locally advanced PC was defined as having one or more of the following parameters: stage $\geq \mathrm{T} 3$ and/or PSA > $20 \mathrm{ng} / \mathrm{mL}$ and/or Gleason score sum 8-10; any stage $\mathrm{T}$ with pelvic nodal involvement; and clinical stage $\mathrm{T} 3 \mathrm{~b}$ or $\mathrm{T} 4$ disease without evidence of nodal involvement or metastasis $[5,6]$. All final prostatectomy specimens were also reviewed according to the guidelines of the 2005 International Society of Urological Pathology (ISUP) by a single uropathologist (Dr. WSP) with 15 years of experience [7].

2.3. Statistical Analysis. The clinicopathological differences between NHT and non-NHT groups were evaluated using Pearson's $\chi 2$ test. The effect of NHT was evaluated by adjusting for significant clinicopathological variables, such as tumor volume percentage and extracapsular extension (ECE). One-to-one nearest neighbor matching using the PS matching technique was conducted with initial PSA level $(<40$ or $\geq 40 \mathrm{ng} / \mathrm{dL})$, biopsied tumor volume percentage $(<50$ or $\geq 50 \%)$, age ( $<65$ or $\geq 65 y$ ), and Gleason score sum ( $<7$ or $\geq 7$ ) as matching variables. The effect of NHT was then reevaluated in 50 matched pairs within the NHT and non-NHT group.

To investigate the effect of NHT on RM positivity, a univariable logistic regression analysis was performed before PS matching to identify variables with a significant association. Then, a multivariable logistic regression model was conducted using backward variable selection with an elimination criterion of $p>0.05$ applied. NHT and other clinical variables with $p$-value $<0.2$ in univariable analysis were entered the multivariable model. Last, a univariable logistic regression was performed after PS matching. To analyze survival, the Cox proportional hazards model was performed to examine the effect of NHT on BCRfree survival and OS. In this study, BCR was defined as a postoperative serum PSA elevation of $>0.2 \mathrm{ng} / \mathrm{mL}$ assessed on two different occasions following a decrease to nondetectable level [8]. The first PSA value of $\geq 0.2 \mathrm{ng} / \mathrm{mL}$ was used to define the time of recurrence. The Cox proportional hazards models were also performed before and after PS matching.

The results were considered statistically significant when two-sided $p$ values were $<0.050$. All analyses were performed using R project version 3.3.3 (The R Foundation, Vienna, Austria) and SAS version 9.4 (SAS Institute Inc., Cary, NC, USA).

\section{Results}

3.1. Patient Demographics. The overall median follow-up period, median BCR-free survival duration, and OS were 49.1 (range, 7.1-148.3) months, 42 (range, 1-48) months, and were not yet achieved, respectively. In the NHT group, the median treatment duration of NHT was 4 months. Table 1 shows the distribution of clinicopathological variables in the NHT and non-NHT groups before and after PS matching. The results showed no differences in the distribution of preoperative clinicopathological factors between the two groups before PS matching, except for initial PSA level, ECE, lymphovascular invasion (LVI), perineural invasion, neurovascular bundle saving, and positive RM. After PS matching, only ECE, LVI, and neurovascular bundle saving were significantly different between the two groups. Other baseline patient demographics by group before and after the PS matching are summarized in Table 1.

3.2. Prognostic Factors for Resection Margin Positivity. The results from the univariable logistic regression model showed that before PS matching, NHT was a significant factor for predicting RM positivity (Table 2); however, it was no longer associated with RM positivity in the multivariate model. Conversely, tumor volume $\geq 50 \%$ and ECE were significant factors for RM positivity in both the univariable and multivariable models. After PS matching, NHT was no longer a significant factor for RM positivity.

\subsection{Prognostic Factors for Biochemical Recurrence and Overall} Survival. Before PS matching, NHT was not a significant prognostic factor for BCR in both univariable and multivariable Cox proportional hazards model results (Table 3). The initial PSA level, ECE, and LVI remained significant independent factors for BCR in the multivariable model. Even after matching, NHT was not a significant factor for BCR $(p=0.554)$. As for OS, there were no significantly associated clinical variables before or after PS matching. Surprisingly, NHT failed to show a significant association with OS (Table 4). 
TABLE 1: Baseline characteristics before and after propensity score matching.

\begin{tabular}{|c|c|c|c|c|c|c|}
\hline \multirow[b]{2}{*}{ Characteristic } & \multicolumn{3}{|c|}{ Before propensity score matching } & \multicolumn{3}{|c|}{ After propensity score matching } \\
\hline & $\begin{array}{l}\text { RRP } \\
\mathrm{N}(\%)\end{array}$ & $\begin{array}{c}\mathrm{RRP}+\mathrm{NHT} \\
\mathrm{N}(\%)\end{array}$ & $p$ value & $\begin{array}{l}\text { RRP } \\
\mathrm{N}(\%)\end{array}$ & $\begin{array}{c}\mathrm{RRP}+\mathrm{NHT} \\
\mathrm{N}(\%)\end{array}$ & $p$ value \\
\hline No. of patients & $97(55.1)$ & $79(44.9)$ & & $50(50.0)$ & $50(50.0)$ & \\
\hline Age & & & 0.710 & & & 0.410 \\
\hline$<65$ & $33(34.0)$ & $29(36.7)$ & & $17(34.0)$ & $21(42.0)$ & \\
\hline$\geq 65$ & $64(66.0)$ & $50(63.3)$ & & $33(66.0)$ & $29(58.0)$ & \\
\hline PSA & & & $<.001$ & & & 1.000 \\
\hline$<40$ & $84(86.6)$ & $37(46.8)$ & & $37(74.0)$ & $37(74.0)$ & \\
\hline$\geq 40$ & $13(13.4)$ & $42(53.2)$ & & $13(26.0)$ & $13(26.0)$ & \\
\hline Biopsy Gleason score sum & & & 0.476 & & & 0.401 \\
\hline$<7$ & $16(16.5)$ & $10(12.7)$ & & $9(18.0)$ & $6(12.0)$ & \\
\hline$\geq 7$ & $81(83.5)$ & $69(87.3)$ & & $41(82.0)$ & $44(88.0)$ & \\
\hline Tumor volume & & & 0.178 & & & 1.000 \\
\hline$<50 \%$ & $62(63.9)$ & $58(73.4)$ & & $31(62.0)$ & $31(62.0)$ & \\
\hline$\geq 50 \%$ & $35(36.1)$ & $21(26.6)$ & & $19(38.0)$ & $19(38.0)$ & \\
\hline \multicolumn{7}{|l|}{ Clinical T stage } \\
\hline 2 & $1(1.0)$ & $3(3.8)$ & & $1(2.0)$ & $1(2.0)$ & \\
\hline$\geq 3$ & $96(99.0)$ & $76(96.2)$ & & $49(98.0)$ & $49(98.0)$ & \\
\hline \multicolumn{7}{|l|}{ Clinical N stage } \\
\hline 0 & $90(92.8)$ & $57(72.1)$ & & $45(90.0)$ & $34(68.0)$ & \\
\hline 1 & $7(7.2)$ & $22(27.9)$ & & $5(10.0)$ & $16(32.0)$ & \\
\hline Extracapsular extension & $60(61.9)$ & $30(38.0)$ & 0.002 & $34(68.0)$ & $22(44.0)$ & 0.016 \\
\hline Seminal vesicle invasion & $37(38.1)$ & $33(41.8)$ & 0.625 & $21(42.0)$ & $20(40.0)$ & 0.839 \\
\hline Lymphovascular invasion or emboli & $32(33.0)$ & $9(11.4)$ & 0.001 & $17(34.0)$ & $6(12.0)$ & 0.009 \\
\hline Perineural invasion & $79(81.4)$ & $52(65.8)$ & 0.018 & $40(80.0)$ & $37(74.0)$ & 0.476 \\
\hline Apex involvement & $25(25.8)$ & $11(13.9)$ & 0.053 & $13(26.0)$ & $7(14.0)$ & 0.134 \\
\hline Lymph node dissection & $86(88.7)$ & $76(96.2)$ & 0.066 & $43(86.0)$ & $49(98.0)$ & 0.059 \\
\hline Neurovascular bundle saving & $47(48.5)$ & $17(21.5)$ & $<.001$ & $25(50.0)$ & $12(24.0)$ & 0.007 \\
\hline Resection margin & $36(37.1)$ & $16(20.3)$ & 0.015 & $19(38.0)$ & $11(22.0)$ & 0.081 \\
\hline Death & $7(7.2)$ & $11(13.9)$ & 0.144 & $6(12.0)$ & $7(14.0)$ & 0.766 \\
\hline
\end{tabular}

The $p$ value was calculated using Pearson's chi-squared test between NHT and non-NHT groups.

TABLE 2: Logistic regression model for resection margin positivity before and after propensity score matching.

\begin{tabular}{|c|c|c|c|c|c|c|}
\hline \multirow{3}{*}{ Variables } & \multicolumn{4}{|c|}{ Before propensity score matching } & \multirow{2}{*}{\multicolumn{2}{|c|}{$\begin{array}{c}\text { After propensity score matching } \\
\text { Univariable analysis }\end{array}$}} \\
\hline & \multicolumn{2}{|c|}{ Univariable analysis } & \multicolumn{2}{|c|}{ Multivariable analysis } & & \\
\hline & OR $(95 \% \mathrm{CI})$ & $p$ value & OR $(95 \% \mathrm{CI})$ & $p$ value & OR $(95 \% \mathrm{CI})$ & $p$ value \\
\hline NHT plus RRP versus RRP alone & $0.43(0.22-0.86)$ & 0.016 & $0.59(0.27-1.30)$ & 0.188 & $0.46(0.19-1.11)$ & 0.084 \\
\hline Age $\geq 65$ & $0.82(0.42-1.60)$ & 0.561 & & & $0.73(0.30-1.74)$ & 0.473 \\
\hline PSA $\geq 40$ & $1.41(0.71-2.79)$ & 0.328 & & & $4.23(1.64-10.93)$ & 0.003 \\
\hline Biopsy Gleason score sum $\geq 7$ & $1.47(0.56-3.91)$ & 0.436 & & & $1.86(0.49-7.15)$ & 0.365 \\
\hline Tumor volume $\geq 50 \%$ & $6.67(3.26-13.62)$ & $<.001$ & $3.68(1.67-8.09)$ & 0.001 & $5.78(2.28-14.63)$ & $<.001$ \\
\hline Extracapsular extension & $9.33(4.04-21.53)$ & $<.001$ & $5.26(2.13-12.96)$ & $<.001$ & $6.29(2.16-18.33)$ & 0.001 \\
\hline Seminal vesicle invasion & $2.86(1.47-5.58)$ & 0.002 & & & $3.07(1.27-7.42)$ & 0.013 \\
\hline Lymphovascular invasion or emboli & $4.67(2.23-9.80)$ & $<.001$ & & & $4.59(1.71-12.28)$ & 0.002 \\
\hline Perineural invasion & $5.93(2.00-17.57)$ & 0.001 & & & $2.42(0.75-7.86)$ & 0.141 \\
\hline Apex involvement & $253.23(32.55-)$. & $<.001$ & & & NA & \\
\hline Lymph node dissection & $1.05(0.32-3.52)$ & 0.934 & & & $0.69(0.15-3.10)$ & 0.631 \\
\hline Neurovascular bundle saving & $0.55(0.27-1.11)$ & 0.094 & & & $0.51(0.20-1.31)$ & 0.165 \\
\hline
\end{tabular}


TABLE 3: Cox proportional hazards model for biochemical recurrence before and after propensity score matching.

\begin{tabular}{|c|c|c|c|c|c|c|}
\hline \multirow{3}{*}{ Variables } & \multicolumn{4}{|c|}{ Before propensity score matching } & \multirow{2}{*}{\multicolumn{2}{|c|}{$\begin{array}{c}\text { After propensity score matching } \\
\text { Univariable analysis }\end{array}$}} \\
\hline & \multicolumn{2}{|c|}{ Univariable analysis } & \multicolumn{2}{|c|}{ Multivariable analysis } & & \\
\hline & $\operatorname{HR}(95 \% \mathrm{CI})$ & $p$ value & $\operatorname{HR}(95 \% \mathrm{CI})$ & $p$ value & $\operatorname{HR}(95 \% \mathrm{CI})$ & $p$ value \\
\hline NHT plus RRP versus RRP alone & $1.05(0.69-1.61)$ & 0.809 & $1.03(0.62-1.72)$ & 0.906 & $0.84(0.47-1.49)$ & 0.554 \\
\hline Resection margin & $1.51(0.97-2.36)$ & 0.071 & & & $2.14(1.18-3.86)$ & 0.012 \\
\hline Age $\geq 65$ & $0.72(0.46-1.10)$ & 0.128 & & & $0.61(0.34-1.08)$ & 0.091 \\
\hline $\mathrm{PSA} \geq 40$ & $2.14(1.40-3.29)$ & 0.001 & $2.23(1.38-3.60)$ & 0.001 & $3.19(1.77-5.76)$ & $<.001$ \\
\hline Biopsy Gleason score sum $\geq 7$ & $2.35(1.13-4.87)$ & 0.022 & & & $2.77(0.99-7.73)$ & 0.052 \\
\hline Tumor volume $\geq 50 \%$ & $1.78(1.15-2.75)$ & 0.010 & & & $2.50(1.41-4.44)$ & 0.002 \\
\hline Extracapsular extension & $2.47(1.59-3.85)$ & $<.001$ & $2.10(1.30-3.41)$ & 0.003 & $5.04(2.48-10.23)$ & $<.001$ \\
\hline Seminal vesicle invasion & $2.20(1.44-3.36)$ & $<.001$ & & & $2.42(1.36-4.30)$ & 0.003 \\
\hline Lymphovascular invasion or emboli & $2.35(1.50-3.68)$ & $<.001$ & $1.85(1.13-3.05)$ & 0.015 & $3.32(1.83-6.00)$ & $<.001$ \\
\hline Perineural invasion & $2.04(1.18-3.51)$ & 0.011 & & & $3.61(1.43-9.17)$ & 0.007 \\
\hline Apex involvement & $1.71(1.05-2.78)$ & 0.031 & & & $2.39(1.26-4.54)$ & 0.008 \\
\hline Lymph node dissection & $1.09(0.47-2.49)$ & 0.845 & & & $2.28(0.55-9.41)$ & 0.256 \\
\hline Neurovascular bundle saving & $0.62(0.39-0.99)$ & 0.045 & & & $0.56(0.30-1.05)$ & 0.070 \\
\hline
\end{tabular}

TABLE 4: Cox proportional hazards model for overall survival before and after propensity score matching.

\begin{tabular}{|c|c|c|c|c|}
\hline \multirow{3}{*}{ Variables } & \multirow{2}{*}{\multicolumn{2}{|c|}{$\begin{array}{c}\text { Before propensity score matching } \\
\text { Univariable analysis }\end{array}$}} & \multirow{2}{*}{\multicolumn{2}{|c|}{$\begin{array}{c}\text { After propensity score matching } \\
\text { Univariable analysis }\end{array}$}} \\
\hline & & & & \\
\hline & $\mathrm{HR}(95 \% \mathrm{CI})$ & $p$ value & $\operatorname{HR}(95 \% \mathrm{CI})$ & $p$ value \\
\hline NHT plus RRP versus RRP alone & $1.35(0.52-3.51)$ & 0.539 & $0.77(0.25-2.38)$ & 0.650 \\
\hline Resection margin & $1.62(0.60-4.38)$ & 0.338 & $1.94(0.63-5.98)$ & 0.250 \\
\hline Age $\geq 65$ & $1.27(0.45-3.55)$ & 0.654 & $1.29(0.40-4.22)$ & 0.669 \\
\hline $\mathrm{PSA} \geq 40$ & $1.04(0.39-2.77)$ & 0.943 & $0.67(0.15-3.04)$ & 0.599 \\
\hline Biopsy Gleason score sum $\geq 7$ & $1.36(0.39-4.75)$ & 0.630 & $0.84(0.23-3.10)$ & 0.795 \\
\hline Tumor volume $\geq 50 \%$ & $2.17(0.82-5.77)$ & 0.120 & $3.01(0.97-9.28)$ & 0.056 \\
\hline Extracapsular extension & $1.03(0.41-2.62)$ & 0.948 & $1.22(0.41-3.65)$ & 0.717 \\
\hline Seminal vesicle invasion & $1.84(0.71-4.77)$ & 0.210 & $1.53(0.48-4.86)$ & 0.471 \\
\hline Lymphovascular invasion or emboli & $0.45(0.10-1.95)$ & 0.286 & $0.70(0.16-3.17)$ & 0.644 \\
\hline Perineural invasion & $2.69(0.77-9.34)$ & 0.119 & $2.22(0.49-10.09)$ & 0.301 \\
\hline Apex involvement & $1.59(0.51-4.94)$ & 0.421 & $3.02(0.87-10.53)$ & 0.083 \\
\hline Lymph node dissection & NA & & NA & \\
\hline Neurovascular bundle saving & $0.62(0.22-1.75)$ & 0.370 & $0.69(0.21-2.23)$ & 0.532 \\
\hline
\end{tabular}

\section{Discussion}

Discussions regarding the efficacy of NHT on RM and survival prognoses are typically met with the issue of different and heterogeneous baseline characteristics of enrolled patients with different tumor burdens in PC [9]. Our research group published two retrospective studies about the efficacy of NHT in PC $[2,10]$, showing that $75.4 \%$ of patients had pathologic RM negative, $19.5 \%$ had undergraded Gleason score, $50.0-57.1 \%$ of BCR rate, and 3.0-5.6\% had nonrecurrent statuses with pT0 until a median follow-up of 59 months. However, both of these studies had a limitation of heterogeneous baseline characteristics.

In order to adjust for this imbalance in the baseline clinicopathological variables between patients with and without NHT, this study evaluated the effect of NHT on three main comparative endpoints (RM positivity, BCR, and OS) between NHT and non-NHT groups using PS matching in patients with locally advanced PC who underwent RP. Utilization of PS matching corrected the baseline differences for disease state and tumor burdens within the two groups and revealed the inefficacy of NHT on decreasing RM positivity, $\mathrm{BCR}$, and OS, which was contrary to previous reports $[2,10$, 11], and which was accorded to the current EAU guideline of PC [3]. The current EAU guideline recommended NHT only for patients with intermediate or high risk $\mathrm{PC}$ if receiving definitive radiation therapy.

The rationale for using NHT in PC was to decrease the size of the prostate volume by inhibiting the growth of hormone sensitive prostate cells and cancer cells. Decreasing prostate size might help clinicians to resect the prostate more efficiently and easily, with less intraoperative comorbidities during RP. However, the results of this study were consistent with those of previous studies that showed that HT did not 
completely eliminate the PC cells. Additionally, the disease states and the survival prognoses (BCR-free survival and OS) were not affected by NHT $[12,13]$. Once androgen deprivation stops after discontinuing HT during intermittent HT, PSA level increases and the tumor may eventually regrow in the resection site. Other studies observed this process in patients with clear RM and without HT, who experienced recurrences at the operative site $[1,14]$. However, some studies, including ours, have reported that patients achieved complete pathological response (about 0.2-5.4\%) after HT, reflecting potential eradication of advanced prostate cancer with androgen deprivation therapy $[2,15,16]$. Patients with pT0 stage PC are expected to have an extremely favorable prognosis, especially in high risk or locally advanced PC. Further studies should be conducted in patients with pT0 after HT.

Previous systemic reviews and meta-analysis reports showed comprehensive assessments of the efficacy of HT when used as NHT with RP for treatment of PC [1]. Similar to this study, there was no improvement in clinically important outcomes for OS, disease-specific survival, or BCRfree survival when NHT was used with RP. This finding was observed despite improvements in putative pathologic surrogate outcomes, such as RM-free positive status (overall incidence in this study, 74.4\%) and pathological downstaging (16.1\%), particularly when NHT was maintained for $>3$ months (data not shown) [17].

In this study, the efficacy of NHT was not statistically significant; however, other studies have shown significant results for prognosis and RM, as well as some specific indicators for those patients with large tumor burdens [18-21]. In these circumstances, NHT should be cautiously discussed with patients and caregivers to make optimal treatment decisions, particularly because there are no phase III randomized controlled trials for NHT. For example, the use of NHT only prior to RP should be discussed in those patients with PC who have a larger prostate adenocarcinoma and a highly expected intraoperative and postoperative morbidity. A recent prospective 10-year NHT phase II study comparing large bulky PC (defined as a tumor $>4 \mathrm{~cm}$ in diameter) or tumor involvement $>50 \%$ of the gland with cancer and nonbulky PC evaluated this issue [21]. The study included 62 patients with T3 or T4N0M0 who were administered NHT with goserelin acetate and flutamide followed by RP. The patients achieved longer progression-free survival (7.5 years) and unreached OS (68\% of 10-year OS) during a median follow-up time of 10.6 years. This result suggested that NHT might have a role in high volume locally advanced PC as an alternative to combined radiation and HT. In contrast, the present study had $90 \%$ of patients staged $>\mathrm{T} 3$, and PS matching showed no significant efficacy of NHT (Tables 2-4). The different results and interpretations between the two studies might be influenced by the androgen blocking agents, durations of NHT, and the adjuvant multidisciplinary and multimodal therapeutic options, such as long-term HT and external beam radiation therapy used after RP, which were not matched between the NHT and non-NHT groups in this study [22-24].
Additionally, administration of RP with NHT for 3 months might not be sufficient for improvement in diseasefree survival compared with RP alone. Meyer et al. demonstrated that patients receiving NHT for more than 3 months had a significantly lower risk of PSA failure than the RP alone group [19]. In the work from the Canadian Urologic Oncology Group in 500 patients [25], a significant difference in BCR rates was not observed at 4 years, whereas continued pathologic benefit and BCR of PC were observed when NHT was used between 3 and 8 months. In the present study, we were unable to control the duration of NHT usage due to the retrospective design.

Another important factor affecting prognoses is the type of drugs used for NHT. In a recent phase II, randomized, open-label study of NHT with degarelix (gonadotropinreleasing hormone [GnRH] receptor antagonist) versus luteinizing hormone-releasing hormone (LHRH) agonist in patients with PC prior to RP, neoadjuvant degarelix alone was associated with higher levels of intratumoral dihydrotestosterone compared to the use of LHRH agonist and bicalutamide, despite similar testosterone levels [26]. Another randomized phase II trial in patients with intermediate and high risk PC who were administered NHT using LHRH agonists alone versus LHRH agonists plus abiraterone acetate prior to RP found that intraprostatic androgen levels of the prostate specimens were significantly reduced in the abiraterone plus LHRH agonist group than in the LHRH agonist alone group. Additionally, a $7.1 \%$ of pT0 rate and a $55.4 \%$ of residual cancer burden/minimal residual disease were reported for the entire cohort [27]. Heterogeneity of NHT drugs might be a confounding factor in the present study, and as such, future randomized controlled trials are required to clarify this issue.

Last important consideration for the use of HT is HTassociated complications. HT has its own local and systemic side effects, secondary to the blockade of androgen hormone $[28,29]$. The side effects from $\mathrm{HT}$ are related to the duration of HT use. Even though short-term NHT before RP is typically used, the beneficiary effect of HT has been shown to occur after more than 3 months $[1,4,18,19,25]$. Clinicians should remain aware of the potential long-term side effects of HT, as severe liver function abnormality (17\%), bowel problems $(8 \%)$, and urinary and sexual (36\%) problems have led to discontinuation of HT [30]. Therefore, further prospective, large-scale studies are needed to determine the true efficacy of NHT; however, the findings from this study do not support the use of NHT in locally advanced PC who underwent RP.

This study had limitations. First, this study had a small sample from a single institution with a short follow-up period. Second, the variations of the specific hormonal treatments, the duration of NHT, timing of treatments, the different antiandrogen agents and no adjustment of lymph node status or other pathological parameters in PS matching might have affected the results from the analyses. However, the clinical significance of this study is the potential to minimize the different baseline clinicopathological characteristics of tumor burden and disease status between groups using PS matching. Further studies with a large number of subjects and long-term follow-up are required, and the effect 
of secondary hormonal agents should also be investigated for their prognostic efficacy with and without androgen deprivation therapy.

\section{Conclusion}

This study showed that NHT was not a significant factor in predicting RM positivity, BCR-free survival, and OS before and after PS matching in patients with locally advanced or high risk localized PC who underwent RP.

\section{Data Availability}

The datasets used and/or analysed during the current study available from the corresponding author (Kang Hyun Lee, uroonco@ncc.re.kr) on reasonable request. The IRB and ethical committee of the National Cancer Center (in Korea) will review the requests because of the patients' information. After the approval of the committee with confirmation of the reasonable requests, the dataset will be freely available. The other contact e-mail besides the corresponding author's email isirb@ncc.re.kr.

\section{Conflicts of Interest}

None of the authors had anything to declare about the conflicts of interest.

\section{Acknowledgments}

This study was supported by the Korean National Cancer Center (grants no. 1810021-1).

\section{References}

[1] M. D. Shelley, S. Kumar, B. Coles, T. Wilt, J. Staffurth, and M. D. Mason, "Adjuvant hormone therapy for localised and locally advanced prostate carcinoma: A systematic review and metaanalysis of randomised trials," Cancer Treatment Reviews, vol. 35, no. 7, pp. 540-546, 2009.

[2] J. Y. Joung, J. E. Kim, S. H. Kim et al., "The prevalence and outcomes of pT0 disease after neoadjuvant hormonal therapy and radical prostatectomy in high-risk prostate cancer," $B M C$ Urology, vol. 15, no. 1, 2015.

[3] N. Mottet, J. Bellmunt, M. Bolla, E. Briers, M. G. Cumberbatch, and M. De Santis, "Guideline on Prostate Cancer," European Urology, vol. 71, no. 4, pp. 618-629, 2017, http://Uroweb.org/ guideline/prostate-cancer/\#6.

[4] C. C. Schulman, F. M. J. Debruyne, G. Forster, F. P. Selvaggi, A. R. Zlotta, and W. P. J. Witjes, "4-Year follow-up results of a European prospective randomized study on neoadjuvant hormonal therapy prior to radical prostatectomy in T2-3N0M0 prostate cancer," European Urology, vol. 38, no. 6, pp. 706-713, 2000.

[5] NCCN Clinical Practice Guidelines in Oncology ${ }^{\mathrm{TM}}$ Prostate Cancer V.1.2011@ 2011 National Comprehensive Cancer Network I, 2011.

[6] S. A. Rosenthal and H. M. Sandler, "Treatment strategies for high-risk locally advanced prostate cancer," Nature Reviews Urology, vol. 7, no. 1, pp. 31-38, 2010.
[7] J. I. Epstein, W. C. Allsbrook Jr., M. B. Amin et al., “The 2005 International Society of Urological Pathology (ISUP) consensus conference on Gleason grading of prostatic carcinoma," The American Journal of Surgical Pathology, vol. 29, no. 9, pp. 12281242,2005

[8] M. S. Cookson, G. Aus, A. L. Burnett et al., "Variation in the definition of biochemical recurrence in patients treated for localized prostate cancer: the American urological association prostate guidelines for localized prostate cancer update panel report and recommendations for a standard in the reporting of surgical outcomes," The Journal of Urology, vol. 177, no. 2, pp. 540-545, 2007.

[9] A. J. Chang, K. A. Autio, M. Roach, and H. I. Scher, "Highrisk prostate cancer-Classification and therapy," Nature Reviews Clinical Oncology, vol. 11, no. 6, pp. 308-323, 2014.

[10] S. H. Kim, W. S. Park, S. H. Kim et al., "Prostate stem cell antigen expression in radical prostatectomy specimens predicts early biochemical recurrence in patients with high risk prostate cancer receiving neoadjuvant hormonal therapy," PLoS ONE, vol. 11, no. 3, p. e0151646, 2016.

[11] M. E. Gleave, S. E. La Bianca, S. L. Goldenberg, E. C. Jones, N. Bruchovsky, and L. D. Sullivan, "Long-term neoadjuvant hormone therapy prior to radical prostatectomy: evaluation of risk for biochemical recurrence at 5-year follow-up," Urology, vol. 56, no. 2, pp. 289-294, 2000.

[12] K.-H. Chang, C. E. Ercole, and N. Sharifi, "Androgen metabolism in prostate cancer: from molecular mechanisms to clinical consequences.", British Journal of Cancer, vol. 111, no. 7, pp. 1249-1254, 2014.

[13] A. Katzenwadel and P. Wolf, "Androgen deprivation of prostate cancer: leading to a therapeutic dead end," Cancer Letters, vol. 367, no. 1, pp. 12-17, 2015.

[14] M. L. Cher, K. Shinohara, S. Breslin, J. Vapnek, and P. R. Carroll, "High failure rate associated with long-term follow-up of neoadjuvant androgen deprivation followed by radical prostatectomy for stage C prostatic cancer," British Journal of Urology, vol. 75, no. 6, pp. 771-777, 1995.

[15] R. Mazzucchelli, F. Barbisan, A. Tagliabracci et al., "Search for residual prostate cancer on pT0 radical prostatectomy after positive biopsy," Virchows Archiv, vol. 450, no. 4, pp. 371-378, 2007.

[16] J. Park, I. G. Jeong, J. K. Bang et al., "Preoperative clinical and pathological characteristics of pT0 prostate cancer in radical prostatectomy," Korean Journal of Urology, vol. 51, no. 6, pp. 386-390, 2010

[17] L. H. Klotz, S. L. Goldenberg, M. A. S. Jewett et al., "Longterm followup of a randomized trial of 0 versus 3 months of neoadjuvant androgen ablation before radical prostatectomy," The Journal of Urology, vol. 170, no. 3, pp. 791-794, 2003.

[18] L. Vaillancourt, B. Têtu, Y. Fradet et al., "Effect of neoadjuvant endocrine therapy (combined androgen blockade) on normal prostate and pro static carcinoma: a randomized study," The American Journal of Surgical Pathology, vol. 20, no. 1, pp. 86-93, 1996.

[19] F. Meyer, L. Moore, I. Bairati, L. Lacombe, B. Têtu, and Y. Fradet, "Neoadjuvant hormonal therapy before radical prostatectomy and risk of prostate specific antigen failure," The Journal of Urology, vol. 162, no. 6, pp. 2024-2028, 1999.

[20] L. Klotz, M. Gleave, and S. L. Goldenberg, "Neoadjuvant hormone therapy: the Canadian trials," Molecular Urology, vol. 4, pp. 233-237, 2000. 
[21] R. K. Berglund, C. M. Tangen, I. J. Powell et al., "Ten-year follow-up of neoadjuvant therapy with goserelin acetate and flutamide before radical prostatectomy for clinical T3 and T4 prostate cancer: Update on southwest oncology group study 9109," Urology, vol. 79, no. 3, pp. 633-637, 2012.

[22] A. E. Marciscano, M. E. Hardee, and N. Sanfilippo, "Management of high-risk localized prostate cancer," Advances in Urology, vol. 2012, Article ID 641689, 11 pages, 2012.

[23] M. Bolla, L. Collette, L. Blank et al., "Long-term results with immediate androgen suppression and external irradiation in patients with locally advanced prostate cancer (an EORTC study): A phase III randomised trial," The Lancet, vol. 360, no. 9327, pp. 103-108, 2002.

[24] M. Bolla, G. van Tienhoven, P. Warde et al., "External irradiation with or without long-term androgen suppression for prostate cancer with high metastatic risk: 10-year results of an EORTC randomised study," The Lancet Oncology, vol. 11, no. 11, pp. 1066-1073, 2010.

[25] M. E. Gleave, S. L. Goldenberg, J. L. Chin et al., "Randomized comparative study of 3 versus 8 -month neoadjuvant hormonal therapy before radical prostatectomy: Biochemical and pathological effects," The Journal of Urology, vol. 166, no. 2, pp. 500506, 2001.

[26] R. K. Sayyid, A. Evans, K. Hersey et al., "A phase II, randomized, open-label study of neoadjuvant degarelix versus LHRH agonist in prostate cancer patients prior to radical prostatectomy," Clinical Cancer Research, vol. 23, no. 8, pp. 1974-1980, 2017.

[27] E. A. Mostaghel, S. T. Page, D. W. Lin et al., "Intraprostatic androgens and androgen-regulated gene expression persist after testosterone suppression: Therapeutic implications for castration-resistant prostate cancer," Cancer Research, vol. 67, no. 10, pp. 5033-5041, 2007.

[28] H. Isbarn, L. Boccon-Gibod, P. R. Carroll et al., "Androgen deprivation therapy for the treatment of prostate cancer: consider both benefits and risks," European Urology, vol. 55, no. 1, pp. $62-75,2009$.

[29] A. S. Neto, M. Tobias-Machado, M. A. P. Esteves et al., "Bisphosphonate therapy in patients under androgen deprivation therapy for prostate cancer: a systematic review and metaanalysis," Prostate Cancer and Prostatic Diseases, vol. 15, no. 1, pp. 36-44, 2012.

[30] D. S. Lamb, J. W. Denham, H. Mameghan et al., "Acceptability of short term neo-adjuvant androgen deprivation in patients with locally advanced prostate cancer," Radiotherapy \& Oncology, vol. 68, no. 3, pp. 255-267, 2003. 


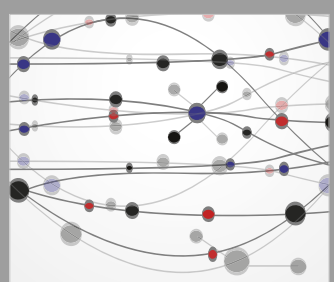

The Scientific World Journal
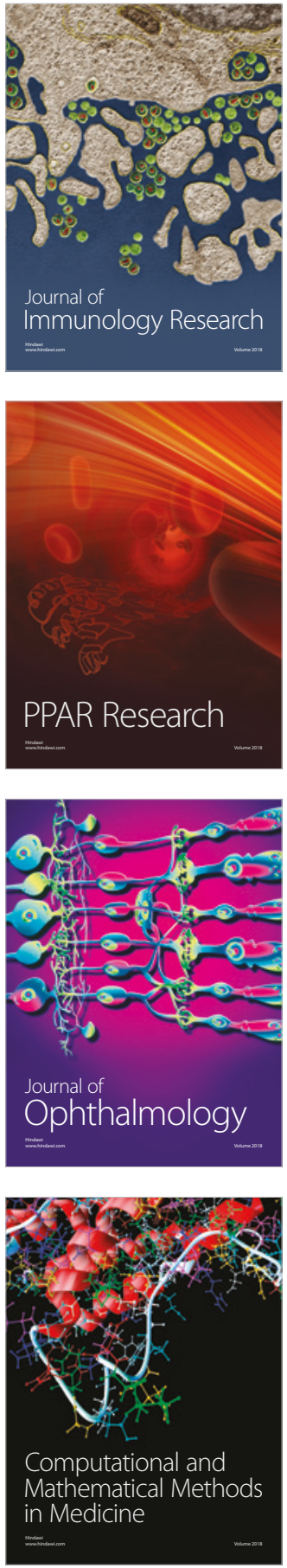

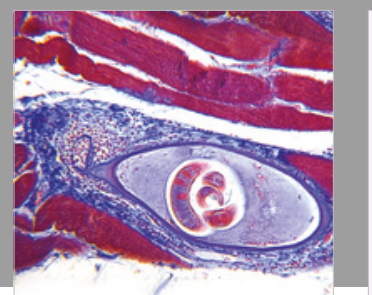

Gastroenterology Research and Practice

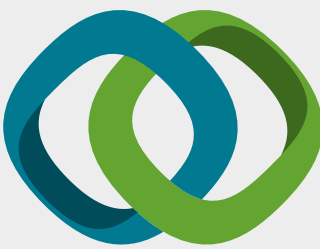

\section{Hindawi}

Submit your manuscripts at

www.hindawi.com
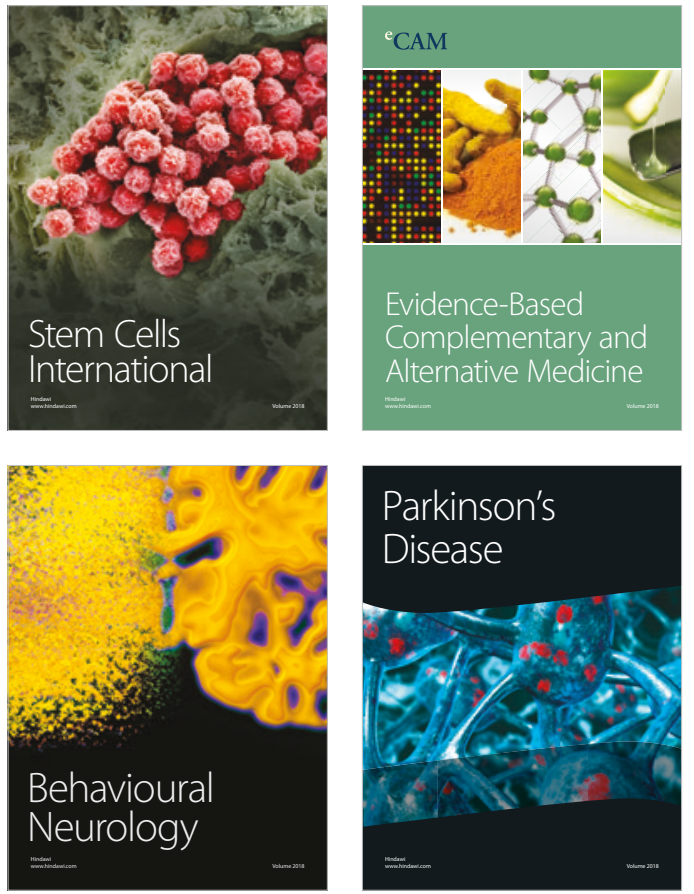

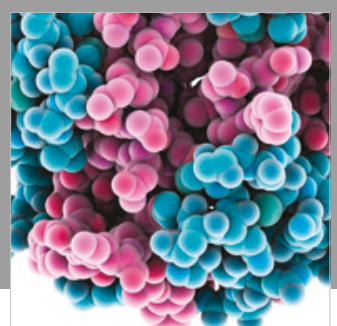

ournal of

Diabetes Research

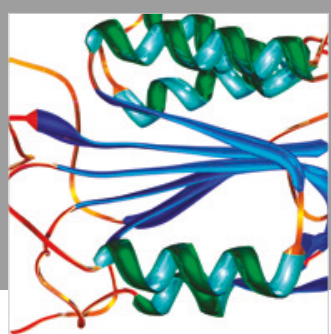

Disease Markers
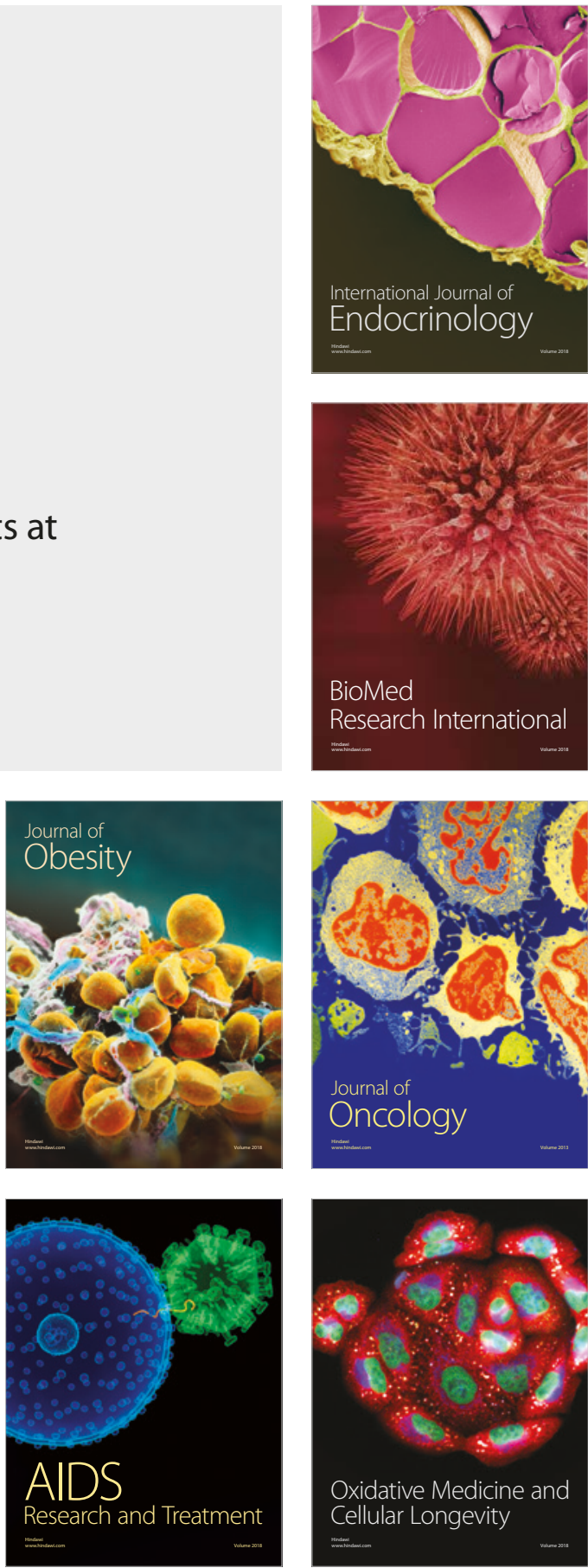